\title{
El Contrato de distribución: de la atipicidad a la formalización
}

\author{
Jaime Vintimilla Saldaña \\ Universidad San Francisco de Quito
}

\begin{abstract}
Resumen
Los contratos de distribución son mecanismos jurídicos que se han caracterizado por ser atípicos y han surgido por iniciativa de las necesidades del mercado gracias a que los empresarios lo han usado en busca de una utilidad económica necesaria para expandir el alcance de sus negocios. Se analiza la naturaleza de estos contratos así como el intento equivocado de su legalización.
\end{abstract}

\begin{abstract}
Distribution contracts are legal mechanisms that have been characterized as atypical and have emerged on the initiative of market needs since the entrepreneurs have used them in search of economic profit to expand the scope of their business. It is analyzed the nature of these contracts as well as the wrong attempt of their legalization.
\end{abstract}

Palabras claves: Contrato / Distribución / Atipicidad / Autonomía / Formalización.

Key words: Contract / Distributorship / Atypical / Free will / Formalization.

Sumario: 1. Introducción 2. Naturaleza jurídica 3. Características del contrato $\mathbf{3 . 1}$ Carácter personalísimo o intuitu personae 3.2. Autonomía Subjetiva 3.3. Permanencia o Estabilidad 3.4 Determinación del ámbito material 3.5. Exclusividad 3.4. Determinación del ámbito material 3.5 Exclusividad 3.6. Bilateral 3.7. Oneroso 3.8. Conmutativo 3.9. Consensual 3.10. Atípico o no regulado 3.11. Legalmente innominado 3.12. No formal 3.13. De colaboración o cooperación 3.14. Ordinariamente celebrado por adhesión 3.15. Contratos marco 4. Énfasis en elementos principales 5. Obligaciones 6. Extinción del contrato de distribución 7. Análisis del Proyecto de Código de Comercio 8. Análisis del contrato de distribución a la luz de la Ley Orgánica de Regulación y Control de Poder de Mercado 9. Conclusión

\section{Introducción}

Los diversos tipos de contratos de distribución, ya sean en sentido genérico, ya sean en sentido estricto, ${ }^{2}$ se han constituido en instrumentos con los que cuenta el or-

\footnotetext{
1 Artículo recibido el 27 de abril y aceptado el 14 de junio de 2016. Agradezco al alumno Jaime Pazmiño por el apoyo brindado para la culminación de la presente investigación.

$2 \mathrm{Al}$ decir de Farina el vocablo "distribución" suele emplearse en el mundo de los contratos comerciales en dos sentidos:
} 
denamiento jurídico para regular el mercado y la economía, a la par de otros como el derecho de la competencia, la propiedad industrial, la protección del consumidor, etc. ${ }^{3}$ Estos contratos reflejan con claridad la evolución del derecho mercantil ${ }^{4}$, pues aparecieron con la finalidad de ganar mercado para los productos de un fabricante o productor donde el legislador ha dejado, en buena parte, en manos de los particulares la organización del comercio. ${ }^{5}$

Debido al surgimiento de la empresa y al hecho que el comercio crece a gran escala, el mercado se ve en la necesidad de desvincular del productor del bien o servicio al consumidor final. ${ }^{6}$ Por lo que, se modifica la relación y aparece un tercero en la cadena de producción de un bien o servicio que es el distribuidor. El distribuidor actúa como agente colocador del bien o servicio al alcance directo del consumidor. Debido a esto los comerciantes se ven en la necesidad de acordar términos y condiciones entre el productor y el distribuidor del bien o servicio.

Seguramente por lo anotado es que el profesor Vladimir Villalba define a la distribución como aquel contrato por el cual el fabricante transfiere bienes producidos parcial o totalmente a un distribuidor quien, asumiendo el riesgo y de manera independiente, los coloca en el mercado dentro de una zona territorial determinada. ${ }^{7}$

Por su parte, en el Derecho Comercial Internacional se habla de contratos de distribución y cooperación para referirse a las técnicas de comercialización de productos y servicios en el exterior que benefician al empresario exportador, pues le garantizan, a bajo costo y de manera eficaz, la posibilidad cierta de contar con una red de distribución estable de sus productos y servicios en otro país, compuesta por empresarios

amplio, de carácter genérico, comprensivo de las diversas formas jurídicas mediante las cuales una persona o empresa, coloca en el mercado bienes o servicios que genera otra empresa (agencia, concesión, etc.), y estricto o restringido, referido a un modo particular de vinculación entre la empresa productora y el sujeto que coloca los productos en el mercado ( Contrato de distribución), es decir, nos hallamos ante una relación contextual que cobra individualidad en cada caso en concreto. Farina, Juan, Contratos comerciales modernos, Astrea, Buenos Aires, 2005, pp 469 y 470. A los contratos de distribución en sentido amplio se los ha colocado en una categoría como una "familia de contratos" y para evitar confusiones se ha usado la expresión "canales de comercialización por terceros independientes". Márquez, José Fernando; Calderón Maximiliano, "Contrato de distribución”, en Contratos de distribución, Heliasta, Buenos Aires, 2010, p 14.

3 Giraldo Bustamante, Carlos Julio, “Algunas reflexiones sobre los contratos de distribución, en especial sobre los contratos de concesión y agencia mercantil”, en Modernización de las Obligaciones y los Contratos, seis estudios, Universidad de los Andes, Bogotá, 2015, p 78.

4 El contrato de distribución nace a partir del escalamiento de producción de bienes y servicios que surge en la Revolución Industrial.

5 Id., p 79.

6 Romero, Jorge, "Regulación jurídica contractual de la distribución comercial”, Revista de Ciencias Jurídicas No. 129. Diciembre, 2012, p. 98.

7 Villalba Paredes, Vladimir, "El contrato de distribución en Contratos mercantiles y bancarios más usuales en los procesos de globalización”, Texto-Guía, Universidad Técnica Particular de Loja, Loja, 2007, pp 58 y 59. 
independientes que colaboran con él, y respecto de la cual cuenta con un cierto nivel de control. ${ }^{8}$

Actualmente en la legislación ecuatoriana no se contempla al contrato de distribución como un contrato típico, es decir, no se encuentra disciplinado en ninguna norma ni aparece definido su régimen específico por medio de ley. Esta figura contractual, eminentemente atípica, más bien se ha vuelto muy común tanto en el mercado ecuatoriano como en el internacional. ${ }^{9}$ En realidad el único cuerpo legal que menciona los acuerdos de distribución es la Ley Orgánica de Regulación y Control del Poder de Mercado para determinar si es que constituye o no una práctica contraria al derecho de la competencia.

Debido a esta relevancia transnacional resulta necesario que se analice qué se entiende por contrato de distribución, qué características tiene, qué elementos lo constituyen y cuál es el tratamiento que la jurisprudencia y la doctrina le han brindado.

Por último, resulta importante analizar, al menos someramente, el Proyecto de Código de Comercio $^{10}$ donde se busca dotar a este contrato de la característica de la tipicidad mediante la cual pasaría a regularse por un régimen legal determinado dentro de lo denominado como sistemas de distribución y otros contratos relacionados.

\section{Naturaleza jurídica}

Como ya se dijo, el contrato de distribución, es un contrato atípico, por el cual una de las partes se obliga a proveer un producto para que la otra parte lo comercialice. Así, Perrota y Couso lo definen como:

Contrato por el cual el productor o fabricante convienen el suministro de un bien final al distribuidor, quien adquiere el producto para proceder a su colocación masiva por medio de su propia organización en una zona determinada, y a cambio de un porcentaje que puede consistir en un descuento sobre el precio de venta del producto. ${ }^{11}$

De esta definición se puede evidenciar algunos aspectos o rasgos fundamentales del contrato como las partes que intervienen en la distribución, las obligaciones principales y varias de sus características distintivas como onerosidad, tracto sucesi-

\footnotetext{
8 Esplugues Mota, Carlos et al., Derecho del Comercio Internacional, Tirant Lo Blanch, Valencia, 2011, p 244.

9 Su importancia es tal que ha suscitado un notable interés por parte de instituciones públicas y privadas, siendo campo abonado para la intervención de la Lex Mercatoria, Ibíd., p 244.

10 El proyecto de Código de Comercio fue presentado por el asambleísta Galo Borja Pérez en noviembre de 2015.

11 Perrota, Salvador; Juan Carlos, Couso, Contratos de Empresa, II Jornadas Rioplatenses de Derecho, n.f., p 173.
} 
vo, consensual, conmutativo, entre otras. Debido a que este contrato es atípico, la doctrina y la jurisprudencia han definido ciertos lineamientos para establecer sus elementos y características, aunque presenta un alto grado de variación debido al hecho cierto que depende de la voluntad de las partes. Así en España, el contrato de distribución depende de lo estipulado por las partes en el acuerdo, aunque Siruaneta además expresa que también deben aplicarse de manera supletoria y por analogía las normas que regulan la compraventa mercantil.

El contrato de distribución es, en España, un contrato atípico de carácter mercantil y que, en consecuencia, se regirá por las estipulaciones que al amparo de la amplísima libertad de contratación consagrada en el artículo 51 del Código de Comercio y 1255 del Código Civil, convengan las partes y, en su defecto, analógicamente, por lo dispuesto para la compraventa mercantil. ${ }^{12}$

En el Ecuador y en la misma línea, como consecuencia de la atipicidad contractual, deberá estarse a lo establecido por las partes en el contrato en virtud de la libertad contractual y de las normas generales de contratación que consagran el código civil y el código de comercio.

El objeto principal del contrato de distribución es colocar en el mercado el bien o servicio que produce el proveedor, por ello José Cano lo define como aquellos contratos donde el objeto es la creación de redes comerciales propias o ajenas para la colocación de los productos o bienes en el mercado. ${ }^{13}$

El Tribunal Supremo español ha determinado que el contrato de distribución tiene por objeto colocar en el mercado los bienes y servicios pero que el distribuidor juega con la diferencia entre el precio de coste y el de transferencia para obtener beneficios ${ }^{14}$. De esto, se entiende que el proveedor vende su producto a un tercero distribuidor para que éste se encargue de la comercialización a cambio de un beneficio que puede ser obtenido de la renta de la compraventa entre el distribuidor y el cliente final.

De acuerdo a Guido y Chavarría el contrato de distribución se define como aquel en el que el fabricante del producto se obliga a suministrar el mismo, al distribuidor quien adquiere la propiedad de los bienes para proceder a la venta de dichos bienes por medio de su propia organización, en una zona determinada y recibiendo a cambio una diferencia económica (renta) entre el precio de compra y el de venta. ${ }^{15}$

12 Siuraneta, David, “Contrato de Distribución”, Contratos más frecuentes en la empresa, n.f. 
No obstante lo anterior, siguiendo a Giraldo Bustamante, las relaciones de distribución de bienes y servicios van mucho más allá de la simple compra y reventa del bien, ya que incluyen, entre otras muchas, y en función del grado de complejidad de la estructura o canal distributivo, ${ }^{16}$ actividades propias de la logística, transporte, gestión de stocks, servicio post-venta, aprovisionamiento de piezas de recambio y su correspondiente servicio, explotación y gestión de derechos de propiedad industrial, etcétera. ${ }^{17}$

\section{Características del contrato}

Más allá de las múltiples visiones desde las cuales se estudia el contrato de distribución ${ }^{18}$, debe quedar muy claro que, por lo general, constituyen contratos de distribución aquellos de duración, determinada o indeterminada, en los cuales el distribuidor adquiere en firme mercancías para su reventa en nombre y por cuenta propia, si bien comprometiéndose a defender los intereses del fabricante o mayorista (la marca), dentro de la disciplina de una red de distribución integrada, conforme lo aclara magistralmente el profesor valenciano Francisco Vicent Chuliá. ${ }^{19}$

Siguiendo nuevamente a Farina, el contrato de distribución es un contrato esencialmente consensual, que se centra en la utilidad o lucro, pues otorga al distribuidor el derecho de vender en un sector determinado, cuya ganancia consiste generalmente, en la diferencia contra el precio de compra y el de venta, denominada comisión o reventa. En todo caso, debe tenerse presente que se trata de un contrato no regulado donde el objeto de distribución tiene un precio de mercado establecido por el productor al cual debe atenerse el distribuidor.

Por último, cabe resaltar que este tipo de contrato, muy frecuentemente, se basa en el riesgo adquirido por el distribuidor, es decir, suscribe un contrato donde en su calidad de distribuidor corre un riesgo, ya que en caso de no pago por parte del cliente, se ve afectado solamente esta parte contractual, pues soporta todos los riesgos, así y

Diciembre, 2012., p. 97

16 Farina, en la misma línea de Márquez y Calderón, explica que para evitar confusiones resulta útil emplear la expresión "canales de comercialización por terceros" ( en vez de distribución, en sentido genérico) para referirse a todo contrato entre una empresa productora o mayorista y otra empresa o persona física no ligada por un contrato laboral, que implica una relación estable, a menudo exclusiva, e importa el compromiso de colaborar para que determinados bienes o servicios se vendan en el mercado nacional e internacional, directamente al público consumidor o bien a otras empresas. No obstante, por razones prácticas, utiliza el término "distribuidor" en sentido genérico, para referirse tanto al concesionario como al distribuidor en sentido estricto o propio y al agente de comercio. Farina, Juan, Contratos comerciales modernos, Astrea, Buenos Aires, 2005., p 470.

17 Giraldo Bustamante, Carlos Julio, Algunas reflexiones, p 81.

18 Los contratos de distribución se estudian principalmente desde tres ángulos: 1 . Desde el Derecho de obligaciones y contratos,

2. Derecho de la competencia, en especial, los acuerdos de distribución y, 3. Derecho de la distribución comercial.

19 Vicent Chuliá, Francisco, Introducción al Derecho Mercantil, 16 a ed., Tirant lo Blanch, Valencia, 2003, p. 683. 
una vez que la mercadería ha quedado a su disposición responde por el deterioro, la pérdida, la falta de pago de sus clientes, etc.

De lo visto, bien se pueden advertir caracteres contractuales necesarios y eventuales. Los primeros hacen alusión a aquellos rasgos que deben encontrarse necesariamente presentes en el contrato de distribución como el carácter personalísimo, la autonomía subjetiva y la permanencia. Los eventuales, por su parte, son características que pueden presentarse o no en el contrato sin que por ello se desnaturalice la figura, entre ellos constan la determinación del ámbito material y la exclusividad. ${ }^{20}$

Conforme la doctrina y la práctica comercial el contrato de distribución debe además se catalogado como bilateral, oneroso, conmutativo, consensual, atípico, innominado, no formal, de duración, preponderantemente de cooperación y ordinariamente celebrado por adhesión.

Resulta muy importante entender las implicaciones de estos caracteres porque de estos se derivan varios elementos y obligaciones del contrato de distribución.

\subsection{Carácter personalísimo o intuitu personae}

El productor, concedente o distribuido toma en consideración la organización del distribuidor y su poder de penetración del producto u objeto del mercado. Es decir, la persona del distribuidor no es para nada indiferente, por cuanto su selección para desarrollar la comercialización en una zona determinada se vincula a ciertas cualidades o experiencia, como su capacidad de penetración comercial, de allí su relación con la exclusividad. Autores como Roque Caivano expresan que también resulta esencial la persona del distribuido, pues "el distribuidor tampoco pondrá en riesgo la confiabilidad de su propia empresa distribuyendo productos que no le merecen la confianza suficiente". ${ }^{21}$

Es decir, se trata de un tipo de contratos personalistas que se construyen sobre la confianza mutua de los contratantes donde juega un papel preponderante las virtudes, capacidades, crédito y condiciones particulares, especialmente del distribuidor, aunque en algunos de ellos las condiciones del fabricante también son determinantes en actividades como la de la franquicia, o como sucede también en muchos casos en la concesión. ${ }^{22}$

\footnotetext{
20 Márquez, José Fernando; Calderón Maximiliano, “Contrato de distribución”, pp. 18 a 22.

21 Ibídem, p. 18.

22 Giraldo Bustamante, Carlos Julio, Algunas reflexiones, p 83.
} 
En definitiva, los contratos intuitu personae son aquellos en los cuales la calidad de la persona que se obliga resulta esencial. Por eso y como consecuencia, los contratos de esta naturaleza se extinguen una vez que la persona natural o jurídica del contrato deja de existir. La importancia de esta característica estriba en el hecho que el proveedor tiene en consideración al distribuidor y lo elije sobre la base de su posición en el mercado, de su capacidad para introducir el producto en el mercado, de su organización económica, técnica y comercial, por lo que se torna trascendental conocer quién es la persona que ejecuta el contrato, ya que no puede hacerlo o ejecutarlo cualquiera otra sino solo aquella con la que se pactó.

\subsection{Autonomía Subjetiva}

El distribuidor y el distribuido no presentan vínculos laborales ni societarios, aunque se advierte la existencia de un habitual predominio del distribuido o productor. No existe entre las partes contractuales una sociedad, ni una relación de control societario externo o interno, más allá de que el contrato pueda ser calificado como de estructura asociativa. El distribuidor resulta ser un empresario autónomo e independiente del distribuido, que realiza la actividad distributiva al beneficio económico derivado del margen de reventa. Tampoco existe representación del distribuido por el distribuidor, aunque aquel ejerce funciones de control respecto del distribuidor, pues no necesariamente el vínculo contractual es estrictamente paritario. ${ }^{23}$ La distribución se entiende como un negocio empresario en el cual el distribuidor actúa en interés y en nombre propios, como un empresario independiente24.

\subsection{Permanencia o Estabilidad}

Implica la idea que el contrato de distribución está estructurado para permanecer en el tiempo, conformando una relación estable entre distribuido y distribuidor, expresada esencialmente en el deber de provisión de productos que genera resultados o expectativas para las partes contratantes. En este sentido, la estabilidad se orienta a la obtención de una legítima expectativa de lucro para el distribuidor y una expectativa de estabilidad en la comercialización de sus productos para el distribuido, por ello se justifica la responsabilidad por ruptura intempestiva de la relación y el requerimiento o interpellatio ${ }^{25}$. En muchos casos se advierte el hecho que el distribuidor ayuda a consolidar una clientela a favor del fabricante durante el tiempo de vigencia

23 Márquez, José Fernando; Calderón Maximiliano, “Contrato de distribución”, pp 19 y 20.

24 Etcheverry, Raúl Aníbal, Derecho Comercial y Económico: Contratos. Parte especial, Astrea, Buenos Aires, 1995 , p. 216.

25 Márquez, José Fernando; Calderón Maximiliano, "Contrato de distribución”, p 21. Revisar el artículo de Ortiz Herbener,

Andrés, "Los Contratos de distribución: la terminación ad nutum y la correspondiente indemnización por clientela", en Revista Jurídica, Facultad de Jurisprudencia y Ciencias Sociales y Políticas de la Universidad Católica de Santiago de Guayaquil, Edición 17, 2004. 
del contrato. ${ }^{26}$

Por ello, Etcheverry explica que la duración tiene un contenido netamente económico para las partes, pues afectan parcial o totalmente sus inversiones y la actividad de sus respectivas empresas a ese fin, en función del plazo de dicho contrato. ${ }^{27}$ En tal virtud, la distribución es un "contrato de duración" que se caracteriza por la previsión de ejecución continuada, pues se demuestra que las partes tienen la plena convicción de que el desenvolvimiento del negocio requiere un apreciable lapso, ya que existen actividades estables y duraderas para cumplir la finalidad económica perseguida por ambas partes contratantes.

\subsection{Determinación del ámbito material}

Este contrato favorece la comercialización de los productos del distribuido en una zona geográfica determinada, ya sea nacional, ya sea internacional así como también se refiere a un mercado específico donde deben explicarse detalladamente los productos o servicios que el distribuidor se encargará de poner a la venta.

\subsection{Exclusividad}

Es una característica que depende de la voluntad de las partes contratantes, es decir, puede pactarse en favor del distribuidor en una zona determinada, aunque también bien se podría considerar que el distribuidor está facultado para comercializar otros bienes y servicios no competitivos, salvo pacto expreso en contrario. La exclusividad a favor del distribuidor importa que el distribuido no puede comercializar en forma directa o por intermedio de terceros los productos cuya comercialización le fue encargada al distribuidor en la zona que le fuera asignada, pues en caso de hacerlo desnaturalizaría el contrato y generaría pérdidas al distribuidor. ${ }^{28}$

\subsection{Bilateral}

Es decir, presenta obligaciones recíprocas para distribuidor y distribuido. En otras palabras, permite el nacimiento de obligaciones para ambas partes, así para el fa-

\footnotetext{
26 Los contratos de distribución pueden ser de tracto sucesivo o de ejecución inmediata. Los últimos son aquellos que tienen eficacia desde su celebración, se extinguen cuando se cumplen sus obligaciones y éstas solo se cumplen una sola vez. Por otra parte, los contratos de tracto sucesivo son aquellos en lo que su ejecución es continuada, es decir, tienen obligaciones periódicas y estas no son exigibles todas al momento de su celebración. La importancia de esta característica en el contrato de distribución se debe a la forma en la que se procede ante el eventual incumplimiento de una de las partes. En los contratos de tracto sucesivo aplica la figura de la terminación.

27 La distribución en todas sus formas necesita de cierto tiempo de duración, para que la empresa distribuidora o representante amortice su inversión, para que el negocio de la segunda empresa se desarrolle y de sus frutos. Etcheverry, Raúl Aníbal, Derecho Comercial y Económico, p. 206.

28 Márquez, José Fernando; Calderón Maximiliano, “Contrato de distribución”, p. 22.
} 
bricante, distribuido o productor la de transferir a título oneroso bienes y, para el distribuidor, a adquirirlos por un precio inferior al precio final en el mercado del consumidor final. ${ }^{29}$ En el Derecho ecuatoriano se entiende por contrato bilateral aquel en el cual existen obligaciones para dos sujetos de derecho. Por su parte, el Código Civil indica que hay contrato bilateral cuando las partes contratantes se obligan recíprocamente.30 Entonces, como ya se expresó, en el contrato de distribución existe una relación contractual bilateral debido a que ambas personas pactan una relación jurídica en la cual las dos comparten obligaciones.

\subsection{Oneroso}

Se parte de la idea que las ventajas que se procuran a una u otra de las partes son concedidas por una contraprestación a su cargo. En este sentido, se trata de una onerosidad compleja, pues tanto en la etapa de provisión de productos como en la de reventa, las prestaciones realizadas por el distribuidor (pago de precio de compra, transferencia de propiedad de productos) se realizan en virtud de una contraprestación (provisión de productos, cobro de precio de reventa), aunque en el segundo momento la contraprestación se encuentra a cargo de terceros o consumidores y no de la otra parte del contrato. ${ }^{31}$

El profesor Villalba es muy claro al decir que se trata de un contrato oneroso porque tanto el fabricante cuanto el distribuidor asumen un detrimento patrimonial en el cumplimiento de su prestación, que se encuentra compensado en la contraprestación. ${ }^{32}$

Al respecto el artículo 1456 del Código Civil dispone que el contrato es oneroso, cuando tiene por objeto la utilidad de ambos contratantes, gravándose cada uno a beneficio del otro. ${ }^{33}$ Así las cosas, el contrato de distribución se entiende un contrato oneroso debido a que existen gravámenes para ambas partes. Esto quiere decir, que ambas partes sufren una alteración en su patrimonio, en el caso del contrato que nos concierne el proveedor disminuye su inventario pero se compensa con el ingreso obtenido por ventas en su activo; por otra parte, el distribuidor incrementa su inventario a cambio del pago de un precio. Por lo que se cumple lo que establece la ley, ya que ambos gravan su patrimonio y obtienen un beneficio.

29 Villalba Paredes, Vladimir, Villalba Paredes, Vladimir, "El contrato de distribución, p 60.

30 Código Civil Ecuatoriano, 2005, artículo 1455.

31 árquez, José Fernando; Calderón Maximiliano, “Contrato de distribución”, p. 22.

32 Villalba Paredes, Vladimir, Villalba Paredes, Vladimir, "El contrato de distribución, p 61.

33 Ibídem. Artículo 1456. 


\subsection{Conmutativo ${ }^{34}$}

El contrato de distribución es conmutativo debido a que las prestaciones se miran como equivalentes, esto quiere decir que las partes conocen de los riesgos del contrato y de las obligaciones que pactan por lo que están de acuerdo a recibir una contraprestación a cambio de la prestación que deben ejecutar. En este sentido, las partes consideran que existe una equivalencia entre lo que dan y reciben en virtud del contrato 35 .

En definitiva, las ventajas o desventajas (pérdidas) para las partes son previsibles, o sea, en el contrato se encuentran predeterminadas desde su perfeccionamiento.

\subsection{Consensual}

Por ser un contrato atípico es un contrato consensual que se perfecciona con el consentimiento. El contrato de distribución se entiende existente el momento en el que las voluntades de ambas partes acuerdan. La jurisprudencia ha determinado que por su característica de atípico no puede ser un contrato solemne.

[E]l contrato de distribución no se encuentra regulado en nuestro ordenamiento jurídico, por lo que al resultar un contrato atípico, no está sujeto, para su validez, a formalidades especiales". ${ }^{36}$

Por lo que, el presente contrato no necesita de ninguna formalidad ni solemnidad para que sea existente o válido sino que es de aquellos contratos que se perfeccionan por el consentimiento de las partes. ${ }^{37} \mathrm{La}$ dificultad que presenta la informalidad del contrato de distribución es la de interpretar la voluntad de las partes y las obligaciones pactadas en dicho contrato.

\subsection{Atípico o no regulado}

Muchos contratos mercantiles son regularmente atípicos, ya que debido al dinamismo del comercio la Ley no puede regularlo todo y además por la necesidad siempre

\footnotetext{
34 Coincido con Giraldo Bustamante en el sentido que la nota de conmutatividad de la relación no es de su esencia; por consiguiente, las partes podrían hacer de uno de estos contratos uno de tipo aleatorio.

35 El artículo 1457 del Código Civil dispone que "el contrato oneroso es conmutativo cuando cada una de las partes se obliga a dar o hacer una cosa que se mira como equivalente a lo que la otra parte debe dar o hacer a su vez".

36 Sala Primera. Sentencia No. 104 del 16 de noviembre de 1994. Romero, Jorge. Regulación jurídica contractual de la distribución comercial. Revista de Ciencias Jurídicas No. 129. Diciembre, 2012.

37 Villalba Paredes sostiene que la distribución es un contrato consensual porque, a falta de regulación expresa, el contrato se perfecciona con el simple acuerdo de las partes (libertad de forma). Empero, por una necesidad ad-probationem, el contrato suele reducirse a instrumento privado al menos.
} 
volátil del mercado existen varios tipos de contratos atípicos o innominados en materia mercantil.

En este sentido, se entiende por contrato atípico aquel que no se encuentra regulado en la ley. Generalmente cuando los contratos son atípicos suelen estar desarrollados por la doctrina, la costumbre o la jurisprudencia. En nuestro país no existe legislación que establezca un régimen para el contrato de distribución y la jurisprudencia ha resuelto muy poco sobre este tema por lo que resulta importante definirlo mediante la doctrina y la jurisprudencia internacional. Además por ser atípico, este es un contrato en el que se ve mayor aplicación del principio de autonomía de la voluntad y las derivaciones de dicho principio como la libertad contractual y la libertad de configuración interna del contrato.

Sin embargo y por contrapartida, este contrato resulta socialmente típico, pues el tráfico negocial ha delineado sus elementos característicos, por ello Villalba Paredes reconoce que es un contrato no reconocido en nuestra legislación, aunque goza de tipología social. ${ }^{38}$

\subsection{Legalmente innominado}

Como lo que ocurre en el caso ecuatoriano, el ordenamiento jurídico no le otorga una denominación o nombre, aunque en la práctica, gracias a la doctrina, la costumbre mercantil y la jurisprudencia se le denomina contrato de distribución. No obstante, Villalba Paredes considera que se trata de un contrato nominado y cita la ley especial belga.

\subsection{No formal}

Para Farina el contrato de distribución es un contrato consensual, en el cual impera la libertad de formas, pudiendo celebrarse, aunque la doctrina no es pacífica, incluso de manera verbal.

\subsection{De colaboración o cooperación}

Si bien supone actos de cambio entre los contratantes o partes como la provisión de productos, el aspecto central que se destaca es la colaboración empresaria o condominio empresaria realizada entre distribuidor y distribuido, tendiente a obtener la mayor rentabilidad posible derivada de la comercialización de productos a terceros. ${ }^{39}$

\footnotetext{
38 Villalba Paredes, Vladimir, "El contrato de distribución, p. 61. También ver: Márquez, José Fernando; Calderón Maximiliano, "Contrato de distribución”, p. 23.

39 Márquez, José Fernando; Calderón Maximiliano, “Contrato de distribución”, p. 24.
} 
Farina señala que la noción de colaboración es amplia en el derecho moderno, y nace de la necesidad de descentralización y complementación que tiene una empresa productora de bienes o servicios, para colocar sus productos en uno o más mercados, función que asume la empresa colaboradora para lograr el fin que ha determinado el advenimiento del contrato. ${ }^{40}$

Etcheverry, establece que la cooperación se vincula al acercamiento y difusión del producto a mercado, y lleva implícita la confianza mutua entre ambas empresas.

Por último, Farina establece que al ser un contrato de colaboración las obligaciones no pueden entenderse como obligaciones individuales, sino de manera integrada porque existe una integración de las partes en la cual hay un deber recíproco de buena fe y de colaborar la una con la otra. ${ }^{41}$

\subsection{Ordinariamente celebrado por adhesión}

En la línea de Giraldo Bustamante, de conformidad a como las partes acuerdan los extremos del contrato, o en otras palabras a su negociación, los contratos de distribución pueden ser negociados o de adhesión. Para Márquez y Calderón habitualmente el distribuido, fabricante, productor o dueño de la marca predetermina el contenido del acuerdo y prefija las obligaciones de las partes, en especial cuanto más integrada es la red de distribución con que cuenta el fabricante.

\subsection{Contratos marco}

Es decir, los fabricantes pueden satisfacer sus necesidades mediante uno o varios contratos de distribución (agencia mercantil, concesión mercantil, franquicia) o de una combinación de ellos. ${ }^{42}$

\section{4. Énfasis en elementos principales}

De la revisión de las características expuestas bien se puede inferir la existencia de elementos principales que permiten determinar con facilidad que se trata de un contrato de distribución.

En primer lugar, en un contrato de distribución concurren dos partes: un distribuidor y un proveedor. El distribuidor es aquella persona que se compromete, principalmente, a colocar el producto o servicio en un mercado determinado. Por otra parte, el

\footnotetext{
40 Farina, Juan, Contratos comerciales, p 471.

41 Ibídem.

$42 \mathrm{Al}$ decir de Etcheverry los contratos de distribución modelo son: a) Distribución mayorista, b) Agencia, c) Concesión y d) Franchising.
} 
proveedor es el fabricante del producto o servicio que se obliga a suministrar el bien objeto del contrato para que éste pueda ser direccionado a los consumidores finales.

Otro elemento principal es la intención de las partes, pues se necesita la voluntad del productor de proveer a un tercero su bien para que éste lo coloque en el mercado y haga llegar el mismo al consumidor final. Por el otro lado, el distribuidor se compromete a colocar en el mercado dicho bien a cambio de una renta. "El concesionario debe realizar la actividad en nombre y por cuenta propia, lo cual implica, no ya en su relación con el concedente, sino en la proyección externa de su actividad, el deber de actuar en su propio nombre en las operaciones de reventa que efectúe con los terceros". 43

Un tercer elemento principal del contrato de distribución, es la independencia entre las dos empresas. Este elemento quiere decir que el distribuidor vende el producto o servicio a nombre propio y a su propio riesgo. Que el distribuidor asuma el riesgo de la venta del producto significa que si el cliente no cumple esto solamente afecta a la empresa distribuidora, mas no al productor del bien o servicio debido a que la obligación de pago por los bienes por parte del distribuidor al proveedor subsiste. Es importante aclarar que no existe representación en el contrato de distribución.

Por la naturaleza atípica del contrato, las partes pueden pactar todo aquello que no atente contra el orden público y en derredor al principio de la libertad contractual, como ya se advirtió ut supra, el contrato de distribución puede ser o no exclusivo.

De acuerdo a Farina, existen ciertos elementos que son comunes en los contratos de distribución, a saber: exclusividad de zona, exigencia de una venta mínima, entrega de la mercadería al distribuidor con un descuento, fecha de pago de las facturas, lugar y forma de entrega de la mercadería y de acopio, precios mínimos de venta, estipulaciones sobre publicidad y acuerdos de no competencia. ${ }^{44}$

\section{Obligaciones}

Para complementar todo lo dicho no se puede dejar de considerar algunas obligaciones que adquieren las partes que suscriben los contratos de distribución.

Debido a su carácter bilateral en el contrato de distribución surgen obligaciones para ambas partes. En el caso del proveedor, la obligación principal es la de entregar el producto al distribuidor de manera periódica en los términos acordados. La doctrina

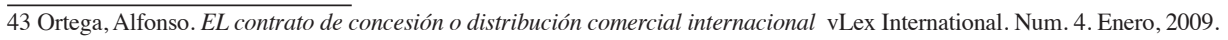
44 Farina, Juan. Contratos comerciales modernos. Buenos Aires: Astrea, 2005, p. 492. 
establece que dentro del contrato de distribución se inserta un contrato de suministro debido a que el fabricante se obliga a distribuir sus productos en una zona determinada a través del distribuidor. ${ }^{45}$

De esta obligación se deriva también la de entregar el bien en la cantidad y calidad acordada en el contrato. Así mismo, el proveedor deberá informar y suministrar al distribuidor todos los materiales y elementos necesarios para que éste pueda realizar su actividad de venta al público.

Otra obligación del proveedor del bien, es la de no realizar actos de distribución de su producto dentro de la zona determinada que se concedió al distribuidor.

Además, la obligación principal del distribuidor es aquella de pagar el precio en la forma, lugar y tiempo debidos, esta obligación se cumple de manera periódica al igual que la entrega de los bienes por parte del proveedor. De igual manera, el distribuidor se obliga a vender dichos productos en una zona determinada y con una cantidad mínima de ventas establecida.

También es obligación del distribuidor aquella de permitir una fiscalización por parte del proveedor de la calidad del producto comercializado.

\section{Extinción del contrato de distribución}

El contrato de distribución puede extinguirse de varias formas, a saber: Consumación del contrato, vencimiento del plazo, imposibilidad de cumplimiento, acuerdo de las partes, resolución por incumplimiento y terminación unilateral.

La primera forma de extinción es aquella que no es contenciosa, es decir, el contrato termina porque se han cumplido en el tiempo y en forma debida las obligaciones previstas por las partes.

Otra forma de extinción del contrato es el vencimiento del plazo o el acontecimiento de la condición resolutoria, por lo que el contrato termina por causas objetivas. En cuanto al plazo vencido del contrato, si es que no existe estipulación de que el contrato termina, se puede extender si las partes, de hecho, continúan con la ejecución periódica de sus obligaciones. ${ }^{46}$

La jurisprudencia española ha determinado que se puede admitir como justa causa de incumplimiento la existencia de una situación patrimonial de crisis o quiebra téc-

45 Farina, Juan. Contratos comerciales modernos. Op. Cit.,, p. 491.

46 Marzorati, Oswaldo. Contratos de distribución. Buenos Aires, Heliasta, 2010. 
nica, otra causa puede ser la desestructuración de la empresa por lo que se pierde la calidad personalísima del contrato.

Se ha admitido como justa causa de desistimiento la situación patrimonial de crisis y quiebra técnica de las partes.

También se admite como justa causa de desistimiento la desestructuración de la empresa por muerte de socio fundador y administrador único, con la consiguiente pérdida de confianza en un contrato intuitu personae como es el de distribución ${ }^{47}$

En cuanto a la resolución por incumplimiento de las partes procede debido a que en todo contrato bilateral va inserta la condición resolutoria tácita. Por lo que cuando existe un incumplimiento declarado por un juez, puede determinar la resolución del contrato. En este sentido, en el caso de Gironella Henrich v. Cooperativa I Caixa de Montbrio del Camp el juez determinó que por el incumplimiento de la cláusula de exclusividad la demandada debería pagar una indemnización. La sentencia establece lo siguiente:

La sentencia de primera instancia estimó íntegramente la demanda: declaró que Montbrio había incumplido el contrato de distribución por infracción del pacto de exclusividad y, consiguientemente, declaró la resolución del contrato de distribución. Además, condenó a la demandada a pagar a la actora la suma de 506.040,80 euros como indemnización de los daños y perjuicios ocasionados con su incumplimiento.

La sentencia fue recurrida en apelación por la demandada. La Audiencia Provincial estimó parcialmente el recurso. En primer lugar confirmó que la demandada había incumplido el pacto de exclusividad y que este incumplimiento justificaba la resolución del contrato de distribución. ${ }^{48}$

En cuanto a la terminación unilateral, la doctrina y la jurisprudencia española han expresado de manera mayoritaria que no es necesario justificar la terminación cuando el contrato ha sido a plazo indefinido. Por lo que se entiende que esta forma de terminación del contrato solo procede cuando el contrato no tiene un plazo. Así, la jurisprudencia se pronuncia por determinar que las cláusulas de un contrato de distribución que establezcan la posibilidad de terminar unilateralmente no son abusivas ni contrarias al orden público.

47 Cordero, Encarna. La extinción y resolución del contrato de distribución en la jurisprudencia Newsletter Pérez-Llorca, Núm. Enero-Marzo 2012.

48 Tribunal Supremo Sala de lo Civil, Sección 1a. Gironella Henrich, S.L.v Cooperativa i Caixa Agraria de Montbrio del Camp. Sentencia num. 615/2012 de 23 octubre 
(..) la jurisprudencia de esta Sala sobre el contrato de distribución hasta esa fecha, y la posterior de 26 de abril del mismo año (recurso núm. 1892/99 ), que ratifica su criterio de decisión, no consideran abusiva ni contraria a las leyes, a la moral, al orden público ni al art. 1256 CC las cláusulas de los contratos de distribución que permitan su extinción por denuncia unilateral del cualquiera de las partes cumpliendo el plazo de preaviso estipulado. ${ }^{49}$

Por último, el Derecho no admite las extinciones absolutamente arbitrarias producto de una decisión unilateral e infundada del principal o distribuido que simplemente se arrogue el derecho de poner fin al contrato con plazo determinado por su "mero arbitrario", ya que las causales anunciadas para ser válidas deben aparecer de forma expresa descritas en una norma jurídica o en las cláusulas contractuales.

En definitiva, no es posible que la parte principal, productor o distribuidor, después de beneficiarse de un contrato que satisfizo sus intereses, decida sin razón o causal alguna - sine causa legibus et contractibus cognita- dar por terminado un contrato y esperar que no cause menoscabo o detrimento a los derechos y a los intereses del distribuidor o lo que es peor que no exista sanción alguna ante semejante inconducta. Este tema ha sido resuelto por la jurisprudencia ecuatoriana que analiza la indemnización por daños y perjuicios causados por incumplimiento de un contrato de distribución..$^{50}$

\section{Análisis del Proyecto de Código de Comercio}

La lege ferenda incorpora los sistemas de distribución que, en general, comprenden todos los contratos celebrados entre fabricantes, proveedores, mayoristas o importadores, y terceros a quienes se les encomienda comercializar en una determinada zona geográfica los productos o servicios de propiedad de los primeros.

De la lectura del artículo 547 del Proyecto se advierte la tipología contractual que conforma los sistemas de distribución y en este sentido se explica que los contratos comprendidos dentro del sistema de distribución de productos o servicios, consisten generalmente en la distribución o concesión, propiamente dicha, cuyas disposiciones comunes se aplican, salvo estipulación especial, a todos los contratos contemplados dentro del título séptimo (distribución o concesión mercantil, franchising y contrato de uso del conocimiento o de know-how).

\footnotetext{
49 Tribunal Supremo (Sala de lo Civil, Sección 1a). Sentencia num. 652/2008 de 9 julio.

50 Visto el incumplimiento contractual, al haber iniciado la distribución directa de los licores importados pese a la vigencia en que se encontraba el contrato, y la terminación unilateral del mismo por parte de ALPACIFIC, se genera el derecho alegado por LIPACSA de reclamar a su contraparte daños y perjuicios. Resolución 60-2008, Segunda Sala de lo Civil y Mercantil publicada en el Registro Oficial 43 de 8 de octubre de 2009.
} 
El capítulo segundo del título séptimo del Proyecto in comento desarrolla el sistema jurídico aplicable al contrato de distribución, así el artículo 548 lo define de la siguiente manera:

Art. 548.- Contrato de distribución de mercaderías es uno por el cual una parte, llamada concedente o principal, confiere a otra llamada, concesionario o distribuidor, la posibilidad de vender los productos que aquella fábrica o que, a su vez, distribuye con capacidad de delegar la distribución a terceros, así como prestar servicios, o una combinación de ambos, de manera continuada o estable, actuando como empresario independiente y asumiendo el riesgo y ventura de tales operaciones.

De su simple lectura se puede evidenciar que el Proyecto reconoce varios elementos para que se perfeccione el contrato de distribución, entre ellos, se encuentran las partes intervinientes: proveedor del bien o servicio y el distribuidor, el carácter de ejecución del contrato y por último la asunción del riesgo de la comercialización. En cuanto a la forma de ejecución del contrato se puede colegir que es uno de tracto sucesivo por lo que de esta característica dependen ciertas otras como la forma de terminación del contrato.

Uno de los elementos más importantes del contrato de distribución es que el distribuidor actúa de manera independiente y asume el riesgo de las operaciones comerciales que incurre éste con los clientes finales del producto o servicio que se encuentra comercializando o distribuyendo. Además, el Proyecto establece que entre el proveedor y distribuidos existe total independencia económica como autonomía jurídica.

El código Civil establece que los negocios jurídicos tienen tres tipos de elementos, entre ellos, los denominados accidentales. A su vez, el artículo 549 del Proyecto reconoce como elementos accidentales, es decir, aquellos que las partes pueden modificar o incluir en el contrato, a las cláusulas respecto al territorio, exclusividad, volúmenes y periodicidad en las compras entre las partes, la forma de remuneración, entre otras.

En el artículo 554 del Proyecto, se establece la forma y cláusulas que debería tener un contrato de distribución. Para mayor entendimiento se cita la norma de la propuesta:

Art. 554.- Los contratos de distribución se celebrarán por escrito y en ellos las partes deberán indicar con claridad el alcance del ejercicio de la distribución, así como los derechos complementarios que ésta conlleve. Deberán, en este caso, señalar: 
1. Identificación precisa de las partes, nombres y apellidos, cédulas de identidad y domicilio de los intervinientes; así como una clara determinación de la calidad que ostentan y con la que concurren a la firma del contrato, es decir, identificando sí obran por sus propios derechos o por lo que representan de un tercero.

2. Describir el contenido y características del negocio objeto de distribución comercial.

3. Duración del contrato así como las condiciones de renovación y modificación del mismo.

4. Formas de remuneración para el proveedor y ventajas económicas para el distribuidor. Causas y efectos de la extinción del contrato incluyendo los casos y la forma en que, cualquiera o ambas partes, lo podrán dar por terminado.

La falta de alguno de estos requisitos hará presumir la existencia de un contrato de distribución, el cual se interpretará de acuerdo con los usos, procedimientos, y costumbres que las partes hayan venido empleando en sus relaciones. Cuando la formalización escrita no se hubiese llevado a cabo por causa a una de las partes, corresponderá a ésta la carga de probar la existencia de las condiciones contractuales que se separen de lo dispuesto en esta Ley.

Al parecer dichos requisitos no son necesarios para la existencia del negocio jurídico en sí, sino que el legislador ha provisto de una lista ejemplificativa de elementos mínimos que deberá contener un contrato de distribución lo cuales si no se encuentran pactados se interpretarán de acuerdo a la costumbre del comercio como ya lo establece el Código de Comercio vigente.

Además, como se mencionó anteriormente, el Proyecto establece ciertas cláusulas que se podrían incluir dentro de un contrato de distribución, entre ellas, el territorio donde se llevará a cabo la distribución, la facultad de delegar o no la distribución a terceros, lo relativo a la propiedad intelectual y la exclusividad o no de la distribución. Todos estos elementos, deben analizarse en conjunto con la Ley Orgánica de Regulación y Control del Poder de Mercado por lo que más adelante se analizarán brevemente las consideraciones pertinentes en esta Ley sobre el contrato de distribución. Por otra parte, se contempla que la falta de remuneración o señalamiento de ella en el contrato conlleva la terminación del mismo. Por ello, el artículo 566 se podría interpretar en el sentido que existe una terminación que se perfecciona por el solo ministerio de la Ley, aspecto que podría generar una inconsistencia debido a que 
significa una terminación ipso iure. A pesar de esto, se contempla la obligación de pago si es que el distribuidor ha vendido algún producto del proveedor.

Conforme a la doctrina y jurisprudencia internacional, el Proyecto de Código de Comercio contempla la terminación unilateral, así el artículo 571 se refiere a los casos en los cuales el contrato de distribución es a tiempo indefinido donde la ley establece un aviso de 90 días de anticipación para que pueda operar la terminación unilateral.

De la misma forma cuando el contrato sea a tiempo fijo se extinguirá por el cumplimiento de lo pactado y se transformará en uno de duración indefinida si las partes continúan cumpliendo sus obligaciones, por lo que el artículo 572 también concuerda con lo que establece la doctrina. Otra forma de terminación procede de manera unilateral y sin preaviso cuando existe incumplimiento total o parcial de alguna de las partes, así cuando hubieren pasado quince días desde el incumplimiento, el contrato podrá ser resuelto y se tendrá derecho a indemnización de daños y perjuicios.

El artículo 577 establece que el distribuidor tendrá derecho a una indemnización cuando concurran una de las siguientes circunstancias:

1. Que por la naturaleza del contrato y por la actividad del distribuidor se hayan incrementado sustancialmente el tipo de operaciones o el número de clientes y que el distribuidor acredite que la clientela seguirá produciendo ventajas sustanciales al proveedor tras la ruptura del contrato.

2. Que se haya establecido un pacto por el cual el distribuidor, una vez extinguido el contrato no pueda hacer competencia al proveedor o al nuevo distribuidor. La duración del pacto de no competencia no podrá exceder un año. Este pacto se tendrá en cuenta exclusivamente a los efectos de la determinación de la indemnización por cliente, sin que tenga la consideración de regulación general sobre los pactos de competencia.

El proyecto da derecho de indemnización al distribuidor por clientela adquirida cuando concurren las circunstancias anteriores, dicha indemnización se encuentra limitada por el artículo 578. En conclusión, el Proyecto de Código de Comercio procede a eliminar una de las características principales al contrato de distribución, esto es, su carácter de atípico, lo que permitía a los acuerdos de distribución y comercialización de bienes y servicios ser siempre más dinámicos y adaptarse a las necesidades del mercado. En consecuencia, si el Proyecto de Código de Comercio llegara a ser aprobado el contrato de distribución se convertirá en un contrato típico regulado, de 
manera estricta, por la Ley, aunque dejando un cierto resquicio a la voluntad de las partes.

\section{Análisis del contrato de distribución a la luz de la Ley Orgánica de Regulación y Control de Poder de Mercado}

Debido a que el contrato de distribución puede generar efectos en el mercado directamente, el Derecho de Competencia ecuatoriano se ha encargado de regular sobre el tema. En este sentido, la Ley Orgánica de Regulación y Control de Poder Mercado establece que los acuerdos que restrinjan, limiten, repartan, paralicen o controlen de manera concertada la distribución son acuerdos prohibidos bajo esta Ley debido a que violan el bien jurídico protegido del derecho de la competencia el cual es la libre competencia y la eficiencia del mercado.

Art. 11.- Acuerdos y prácticas prohibidas.- Están prohibidos y serán sancionados de conformidad con las normas de la presente ley todo acuerdo, decisión o recomendación colectiva, o práctica concertada o conscientemente paralela, y en general todos los actos o conductas realizados por dos o más operadores económicos, de cualquier forma manifestados, relacionados con la producción e intercambio de bienes o servicios, cuyo objeto o efecto sea o pueda ser impedir, restringir, falsear o distorsionar la competencia, o afecten negativamente a la eficiencia económica o el bienestar general. En particular, las siguientes conductas, constituyen acuerdos y prácticas prohibidas: 2. Repartir, restringir, limitar, paralizar, establecer obligaciones o controlar concertadamente la producción, distribución o comercialización de bienes o servicios. ${ }^{51}$

Debido a que los contratos de distribución pueden ser considerados prácticas anticompetitivas, la Ley ha establecido condiciones que deben concurrir para que estén exentos de la prohibición del artículo anterior.

Art. 12.- Exenciones a la prohibición.- Están exentos de la prohibición contenida en el artículo anterior los acuerdos que contribuyan a mejorar la producción o la comercialización y distribución de bienes y servicios o a promover el progreso técnico o económico, sin que sea necesaria autorización previa, siempre y cuando se cumplan todas las siguientes condiciones:

\begin{tabular}{lllllrr} 
a. Permitan a & los & \multicolumn{2}{c}{ consumidores } & o & usua- \\
rios & participar de & forma equitativa de & sus & ventajas; \\
b. No impongan & restricciones que no sean indispen-
\end{tabular}


sables para la consecución de aquellos objetivos; y, c. No otorguen a los operadores económicos la posibilidad de eliminar la competencia respecto de una parte sustancial de los productos o servicios contemplados. ${ }^{52}$

Es importante tomar en cuenta, lo establecido en el artículo precedente al momento de redactar un contrato de distribución debido a que puede ser susceptible de ser determinado como una práctica anticompetitiva por el órgano de control, la Superintendencia de Regulación y Control del Poder de Mercado.

\section{Conclusión}

En la actualidad el contrato de distribución no se encuentra regulado por lo que continúa siendo un contrato atípico. Además, la jurisprudencia, la costumbre y la doctrina han determinado ciertos lineamientos y requisitos generales para que exista un contrato de distribución. Debido a que no se encuentra regulado por ley en este tipo de contratos prima la autonomía de la voluntad de las partes y se deberá estar a ello siempre que se interprete un acuerdo de esta naturaleza. Resulta importante recalcar que el Proyecto de Código de Comercio establece un régimen legal para el contrato de distribución, pero al ser tan delimitado bien podría provocar que este contrato pierda la flexibilidad y el dinamismo necesario impuestos por el mercado y el derecho mercantil, por lo que a pesar de que aparentemente brinda cierta claridad para resolver controversias, no es tampoco lejana la posibilidad de que pueda anquilosarse o estancarse conforme evoluciona el derecho comercial.

En este mismo sentido, se advierte en Colombia el hecho que no resulta necesario o justificado tipificar los contratos de distribución como el de concesión como tampoco debe su evolución estar marcada por su legalización, ya que por una parte los elementos de estos contratos han sido marcados al ritmo de la evolución del comercio, han sido determinados, por la práctica comercial, por las necesidades del comercio; siguiendo la centenaria tradición del derecho comercial, los comerciantes han creado y lo siguen haciendo, los instrumentos jurídicos que les permitan desarrollar su actividad, y, además, su formalización muy probablemente haría que se quedaran rezagados frente a un mundo económico en permanente cambio. Entonces, uno de los riesgos que tienen los contratos de distribución es precisamente su "formalización" o "legalización", pues como en Colombia podrían gestar costosas experiencias. Por ello, el Estado seguirá protegiendo al mercado con normas de orden público que le eviten distorsiones o abusos, pero no legislando los contratos de distribución ${ }^{53}$.

52 Ibídem. Artículo 12.

53 Giraldo Bustamante, Carlos Julio, Algunas reflexiones sobre los contratos de distribución, en especial sobre los contratos de 


\section{Bibliografía}

Cano, José, Manual práctico de contratación mercantil, Madrid, Editorial Tecnos, 2010.

Cevallos Vásquez, Víctor, Manual de Derecho Mercantil, Quito, Editorial Jurídica del Ecuador, 1995.

Cordero, Encarna, "La extinción del contrato de distribución en la jurisprudencia", Newsletter Pérez-Llorca, Núm. Enero - Marzo, 2012.

Esplugues Mota, Carlos et al. Derecho del Comercio Internacional, Tirant Lo Blanch, Valencia, 2011

Etcheverry, Raúl, Derecho comercial y económico, Buenos Aires, Astrea, 1995.

Farina, Juan, Contratos comerciales modernos, Buenos Aires: Astrea, 2005.

Giraldo Bustamante, Carlos Julio, "Algunas reflexiones sobre los contratos de distribución, en especial sobre los contratos de concesión y agencia mercantil”, en Modernización de las Obligaciones y los Contratos, seis estudios, Universidad de los Andes, Bogotá, 2015.

Girard, Lucas, "Responsabilidad del concedente de contratos de distribución por invasiones producidas en zonas otrogadas en exclusividad", n.f.

Guerrero, Diana, La facultad de modificación unilateral en los contratos de distribución de acuerdo con la jurisprudencia arbitral, Universidad del Rosario, Bogotá, 2010.

Hispajuris, Causas de resolución del contrato de distribución y agencia e indemnizaciones, Marzo, 2010.

Márquez, José Fernando; Maximiliano, Calderón, Contrato de distribución, en Contratos de distribución, Heliasta, Buenos Aires, 2010.

Marzorati, Oswaldo, Contratos de distribución, Buenos Aires, Heliaste, 2010.

Ortega, Alfonso, "El contrato de concesión o distribución comercial internacional", Lex International- Num 4, Enero 2009.

Ortiz Herbener, Andrés, “Los Contratos de distribución: la terminación ad nutum y la correspondiente indemnización por clientela", en Revista Jurídica, Facultad 
de Jurisprudencia y Ciencias Sociales y Políticas de la Universidad Católica de Santiago de Guayaquil, Edición 17, 2004.

Palau y Jímenez. Distribución Comercial, http://pjabogados.com.ar/notas/el-contratode-distribucion.pdf (acceso: 1/2/2016)

Perez, Encarnación; Trigo, Eduardo, "La última posición de la jurisprudencia sobre la indemnización por clientela en los contratos de distribución", Actualidad Jurídica, Uría Menéndez, 2008.

Perrota Salvador; Juan Carlos, Couso, “Contratos de Empresa”, II Jornadas Rioplatenses de Derecho, s.f.

Rodríguez, Nuri et. al., Contratos de Distribución. http://www.derechocomercial.edu. uy/ContratosDistribGeneral.htm, (acceso: 29/01/2016)

Romero, Jorge, "Regulación jurídica contractual de la distribución comercial”, Revista de Ciencias Jurídicas No. 129. Diciembre, 2012.

Siuraneta, David, "Contrato de Distribución", Contratos más frecuentes en la empresa, n.f.

Vicent Chuliá, Francisco, Introducción al Derecho Mercantil, 16 ed., Tirant lo Blanch, Valencia, 2003

Villalba Paredes, Vladimir, "El contrato de distribución en Contratos mercantiles y bancarios más usuales en los procesos de globalización”, Texto-Guía, Universidad Técnica Particular de Loja, Loja, 2007.

\section{Legislación y sentencias}

Asamblea Nacional del Ecuador, Proyecto de Código de Comercio, Presentado en 2015.

Cámara Nacional de Apelaciones en lo Comercial de Argentina, Caso No. AJG2 del 24 de Octubre de 2006.

Cámara Nacional de Apelaciones en lo Comercial Argentina, Caso Casa Baekte Secpa C v. Posadas Refrescos S.A. 23 de diciembre 1992.

Código Civil Ecuatoriano, 2005.

Corte Nacional de Justicia de Ecuador, Segunda Sala de lo Civil y Mercantil. Resolu- 
ción 60-2008, Registro Oficial 43 de 8 de octubre de 2009.

Ley Orgánica de Regulación y Control de Poder de Mercado, 2011.

Tribunal Supremo Sala de lo Civil de España, Sección 1a. Gironella Henrich, S.L. v Cooperativa i Caixa Agraria de Montbrio del Camp. Sentencia num. 615/2012 de 23 octubre

Tribunal Supremo de España, Sala de lo Civil, Sección 1a). Sentencia num. 652/2008 de 9 julio

Tribunal Supremo de España, Sala de lo Civil. Sentencia No. 651-2008. aspx?id=708A 5BB019AF1186D56C118C066D28AD807F1942\&type=ROEpagenum=1 (acceSO: $12 / 03 / 2016)$

Código del Trabajo Ecuatoriano (Registro oficial Suplemento 167, publicado el 16 de diciembre de 2015) Disponible en: http://www.silec.com.ec/Webtools/LexisFinder/DocumentVisualizer/DocumentVisualizer.aspx?id=LABORAL-CODIGO_DEL_TRABAJOEquery=CODIGO\%20TRABAJO (acceso: 14/02/2016) 